\title{
Socio-demographic characteristics of the association between knowledge of antibiotic therapy and prudent use in Ghana
}

\author{
Tamara Jimah ${ }^{1}$, Oladele Ogunseitan ${ }^{1}$ \\ 1 Department of Population Health \& Disease Prevention, University of California, Irvine, USA \\ Keywords: stewardship, gender, prevention, knowledge and attitudes, community, antibiotic resistance, antibiotic use, age, ghana \\ https://doi.org/10.29392/001c.12838
}

\section{Journal of Global Health Reports}

Vol. 4, 2020

\begin{abstract}
Background
Increasing resistance of bacterial infections to current treatment threatens to derail progress made to reduce the global burden of diseases. Inadequate knowledge about prudent use of antibiotics is considered a determinant of increasing risks of antibiotic resistance. However, there is insufficient research on effective ways to target information that could increase public knowledge toward improvement of antibiotics stewardship. The aim of this study was to assess the association between knowledge and use of antibiotics in Ghana.
\end{abstract}

\begin{abstract}
Methods
Four hundred residents of the Greater Accra and Upper West regions of Ghana, aged 18 years and older, who had previously used antibiotics, completed a standardized questionnaire survey during the months of September-October 2018. The survey collected information on individual knowledge, attitudes, and practices related to antibiotics and antibiotic resistance. Principal component and multivariate analyses were conducted to determine the different components of knowledge and their association with antibiotic use.
\end{abstract}

\begin{abstract}
Results
Two main principal components were identified; (i) knowledge about treatment of common illnesses (ii) knowledge about prudent use of antibiotics. There was a significant association between gender and the first component, with women having higher knowledge about the treatment of malaria, headaches, and body aches (beta, $b=0.25$; $\mathrm{P}<0.05$; 95\% confidence interval, $\mathrm{CI}=0.01-0.48$ ). Similarly, older individuals aged 25-54 years scored significantly higher than the referent 18-24-year group. The second component revealed significant differences in age, education, and residence, with older adults, persons with higher educational attainment, and Greater Accra residents exhibiting better knowledge about the prudent use of antibiotics for bacterial infections. Likewise, the odds of using antibiotics appropriately was 1.4 times higher for individuals with knowledge about the prudent use of antibiotics (adjusted odds ratio, AOR=1.40; $\mathrm{P}<0.01 ; 95 \% \mathrm{CI}=1.15-1.69)$. Participants who had received a medical prescription during the last occurrence of illness had better knowledge about the treatment of gonorrhea and bladder/urinary tract infections and were knowledgeable about the risks of sharing and buying antibiotics, compared to individuals who had not received a prescription.
\end{abstract}

\section{Conclusions}

Age, gender, residence, education, as well as experience with antibiotics therapy were identified as determinants associated with knowledge of antibiotics and their uses, thereby providing opportunities to improve community-level antibiotics stewardship.

Therapy with antibiotics against pathogenic bacteria has saved millions of lives worldwide. However, antibiotic resistance is becoming an increasingly major concern for global health given its potential to derail advances made to control the spread of resistant pathogens. ${ }^{1-6}$ Bacteria are gradually developing resistance to multiple antibiotics, ${ }^{5,7-9}$ making it impossible to cure infections using standard protocols. Adverse consequences include high medical costs, risks of disease complications, prolonged hospitalization which further increase the chances of contracting nosocomial infections and death. ${ }^{6,10}$ Recent projections indicate high antimicrobial resistance-related mortality rates, with 
over eight million deaths per year in Africa and Asia alone, and a global economic loss of USD100 trillion by $2050 .^{11}$ Moreover, multidrug-resistant infections are beginning to emerge in communities outside of the hospital setting. ${ }^{12}$ In a recent study that included Ghana, African countries reported the highest prevalence of therapeutic-antimicrobial prescriptions ( $\mathrm{n}=1213 ; 57.4 \%)$ for community-acquired infections in adult inpatients. ${ }^{13}$

Although the emergence of antibiotic-resistant pathogenic strains is a natural phenomenon caused by the growth, replication, and mutations of bacteria, ${ }^{14}$ the inappropriate use of antimicrobials such as antibiotics accelerates this process and diminishes drug efficacy. ${ }^{4,15}$ Particularly, widespread misconceptions about the potency of antibiotics for various ailments have led to unnecessary use and self-medication practices in communities. ${ }^{16}$ A systematic review of thirty-four studies found antibiotics and antimalarials to be the most frequently used for self-medication in resource-low settings. ${ }^{17}$ In Ghana, malaria and bacterial infections as meningitis, tuberculosis, and other lower respiratory infections constitute the top causes of death and years lived with disability. ${ }^{18}$ Inappropriate use of antibiotics for the treatment of non-bacterial infections will only accelerate resistance of pathogens and consequently result in futile treatment efforts in cases when these medicines are most needed.

Knowledge about antibiotics and resistant infections has been found to influence antibiotic use. ${ }^{19-21}$ Understanding the different factors that lead to inappropriate antibiotic use may help mitigate this global health problem through effective antibiotic stewardship programs to promote rational use of medicines in communities. Age, gender, education level, and socio-economic status have been hypothesized to predict typology of antibiotic knowledge and use. ${ }^{22-27}$ For instance, studies show that younger individuals, those with lower educational attainment, rural residents, and men exhibited lower knowledge and were more likely to misuse antibiotics, although it is unclear the extent to which the conclusions are generalizable. ${ }^{22-26}$

Identifying predictors of inappropriate antibiotic use could provide important information about the specific knowledge and behaviors to target during the development and implementation of public health interventions and will subsequently promote prudent use of antibiotics in communities. Ghana has taken steps in the last decade to address the problem of drug resistance evidenced by the formation of the Policy on Antimicrobial Use and Resistance and the National Action Plan (NAP) based on the Global Action Plan. ${ }^{28-31}$ One of the key strategic objectives of the NAP is to improve public awareness about antibiotic resistance. ${ }^{28}$ This study therefore aimed to inform implementation efforts by identifying predictors of antibiotic knowledge, and to examine whether the different dimensions of knowledge are significantly associated with the use of antibiotics in Ghana. To do this, we first conducted a Principal component analysis (PCA) to identify different dimensions of knowledge of antibiotic use. We then conducted multiple linear regression analyses to assess the association of different demographic characteristics with the dimensions of knowledge, and subsequently examined whether the components of antibiotic knowledge were associated with appropriate antibiotic use. Our study identified significant predictors of antibiotic use to guide the development of educational materials for effective public health communication.

\section{METHODS}

\section{RESPONSIBLE CONDUCT OF RESEARCH AND ETHICS}

This research study was approved by the Ethics Committee of the Institute of Statistical, Social, and Economic Research at the University of Ghana, Legon (ECH \# 106/17-18), and the Institutional Review Board of the University of California, Irvine (HS\# 2018-4325). All data were securely stored in a passcode-protected laptop by the principal investigator.

\section{DATA COLLECTION}

The research was conducted in the Greater Accra (GAR) and Upper West (UWR) regions of Ghana from September to October 2018. Surveys were administered in twelve sites; Osu, Korle- bu, University of Professional Studies, A\&C shopping mall, Kasoa, Makola, University of Ghana, Legon, Accra shopping mall, Jagbanyiri, Wa regional hospital area, University of Development Studies, Melcom shopping center. Training on research ethics, survey administration, participant recruitment, data quality, and interview procedures was provided to all research assistants (RAs). RAs screened participants for eligibility prior to administering the surveys. Only individuals aged 18 years and older, who had previously used antibiotics were included in the study. Also, eligibility was restricted to persons able to understand, read, and speak English and/or one of the languages predominantly spoken in Accra and Wa (i.e., Akan, Dagaare, Ga, or Waale). The interview was conducted in English and translated to the local languages by trained RAs where necessary. All participant information collected was unidentifiable. Four hundred surveys were administered in total, with 200 per region. Participants were recruited via convenience sampling, and each survey lasted 20-30 minutes. All participants received a soft drink and informational leaflets on antibiotic resistance after completing the questionnaire.

\section{DATA INSTRUMENT AND VARIABLES}

The 2015 Antibiotic Resistance: Multi-Country Public Awareness Survey was adapted for this study. The questionnaire survey was closed-ended and composed of twentynine questions related to individual knowledge, attitudes, and practices regarding antibiotics.

Antibiotic knowledge: We included 17 questions about antibiotic knowledge (eight questions pertaining to knowledge about the effectiveness of antibiotic treatment for a list of infections, three questions relating to knowledge about antibiotic use, and six questions about antibiotic resistance). The response options for each item included True, False, Yes, No, Don't know, Cannot remember. For example, Question: "It's ok to use antibiotics that were given to a friend or family member, as long as they were used to treat the same illness" Response: True/False/Don't know". For descriptive and bivariate statistics, we created a single overall score across the 17 items. 
Antibiotic use: This was defined based on whether the respondent received a medical prescription at the last time of illness. The variable was coded binary, i.e., correct and incorrect response. Any response other than the correct was categorized as incorrect.

Covariates: We considered demographic characteristics as correlates of antibiotic knowledge and as covariates in the association between knowledge and use of antibiotics: region (Greater Accra, Upper West), gender (female, male), education (primary or lower, junior high school, senior high/vocational school, tertiary), and age (18-24; 25-34; $35-44 ; 45-54 ; 55-64 ; 65+)$. Covariates were selected based on prior research that found significant differences in these groups. $^{22,24,25}$

\section{DATA ANALYSIS}

First, we conducted descriptive analyses for overall scale score, reporting absolute frequencies, percentages, means, and standard deviations. We then assessed the dimensionality of the 17-item scale for antibiotic knowledge using PCA. PCA is a statistical technique for reducing the dimensionality of a dataset and for mitigating the problem of multicollinearity. ${ }^{32}$ This method produces new orthogonal variables, which we consider distinct dimensions, while retaining as much variability in the data as possible. Detailed information on the PCA process is given by Joliffe. ${ }^{32}$ For the purposes of this analysis, we retained components that accounted for at least $10 \%$ of the total variance in the data. Correlations above 0.35 were considered significant. Confirmatory tests using Cronbach's alpha were also performed to ascertain the internal consistency of the components derived, hypothesizing that the PCA classifications will produce adequate reliability above 0.5 for an exploratory study. A composite variable was generated from the items of each principal component and assigned labels based on the concepts they represented. Subsequently, we conducted two multivariate linear regression analyses. The first determined the association between demographic characteristics and each of the newly derived principal components. The second examined the association between the identified principal components and antibiotic use, net of the covariates of interest. Adjusted odds ratios and 95\% confidence interval results were reported.

\section{RESULTS}

\section{DESCRIPTION OF THE DATA}

A total of 400 individuals completed the survey, with approximately $7 \%$ more male than female participants. There was an equal representation from the Greater Accra and Upper West regions. About two-thirds of the sample was between the ages of 18-34 years. Thirteen percent had a primary school education or lower. The average overall antibiotic knowledge score for the sample was 10.10 out of a total of 17 points, with a standard deviation of 3.09. About twothirds $(275 / 400 ; 68.8 \%)$ of the participants had received a medical prescription at the last time of illness. Table 1 shows the characteristics of participants in the sample. The frequencies within regions for each of the 17 individual items are presented in Table 2. With the exception of educa- tion, there were no significant differences in age and gender distributions between regions.

\section{PRINCIPAL COMPONENT ANALYSIS RESULTS}

The principal component analysis identified five components with an eigenvalue greater than 1 based on Kaiser's criterion. ${ }^{32}$ These five components explained $51.9 \%$ of the total variance in the data. Of these, the top two components each explained more than $10 \%$ of the total variance with a Cronbach alpha above 0.5 and were therefore retained for further analyses. All seven variables identified for components 1 and 2 had positive scores, indicating an association with higher knowledge. Table 3 shows the principal components generated with their respective variables and loadings. Component 1 explained $16.3 \%$ of total variance and included the following variables; malaria, body aches, and headaches. This component was therefore assigned the label knowledge about treatment of common illnesses. The second component, knowledge about prudent use of antibiotics, explained $10.9 \%$ of total variance, and loaded high on the following variables; gonorrhea, bladder/urinary tract infections, and knowledge about buying and sharing antibiotics (Table 3).

\section{MULTIVARIATE REGRESSION RESULTS}

Table 4 presents the results of the ordinary least squares (OLS) examining the association between region, gender, age, and education and each of the principal components. There was a significant positive association between gender and component 1 , with women having higher knowledge about the treatment of common illnesses as malaria, headaches, and body aches (beta, $b=0.25 ; P<0.05$; $95 \%$ confidence interval, $\mathrm{CI}=0.01-0.48)$. Similarly, individuals aged 25-44 years scored significantly higher than the referent 18-24-year group. There were no differences in mean Component 1 scores for each of the educational categories when compared to the reference group. In contrast, significant differences were observed for component 2, with higher knowledge reported for persons with higher educational attainment. Likewise, individuals between the ages of 35-64 years reported better knowledge than the referent 18-24-year group for component 2. With regard to place of residence, individuals in the Upper West region were less knowledgeable about prudent use of antibiotics, compared to residents of the Greater Accra region. The former scored 0.3 points lower for every unit increase in knowledge about the effectiveness of antibiotics for the treatment of gonorrhea and bladder/urinary tract infections and the buying and sharing of antibiotics.

In Table 5, we present the regression output for the association between the principal components and antibiotic use. After adjusting for region, gender, age, and education, component 2 was significantly associated with appropriate antibiotic use; the odds of using antibiotics appropriately was 1.40 times higher for individuals with knowledge about prudent use of antibiotics (adjusted odds ratio, $\mathrm{AOR}=1.40$ $P<0.01 ; 95 \%$ CI $=1.15-1.69)$. 
Table 1. Characteristics of the sample $(n=400)$

\begin{tabular}{|c|c|}
\hline Characteristics & n (\%) \\
\hline \multicolumn{2}{|l|}{ Independent variables } \\
\hline Region & $200(50.0)$ \\
\hline Greater Accra & $200(50.0)$ \\
\hline \multicolumn{2}{|l|}{ Upper West } \\
\hline Gender & $213(53.3)$ \\
\hline Male & $187(46.8)$ \\
\hline \multicolumn{2}{|l|}{ Female } \\
\hline Age & $129(32.3)$ \\
\hline $18-24$ & $134(33.5)$ \\
\hline $25-34$ & $67(16.8)$ \\
\hline $35-44$ & $38(9.5)$ \\
\hline $45-54$ & $25(6.3)$ \\
\hline $55-64$ & $7(1.8)$ \\
\hline \multicolumn{2}{|l|}{$65+$} \\
\hline Education & $52(13.0)$ \\
\hline Primary school or lower & $22(5.5)$ \\
\hline Junior high school & $107(26.8)$ \\
\hline Senior high/vocational school & $219(54.8)$ \\
\hline \multicolumn{2}{|l|}{ Tertiary/currently enrolled } \\
\hline Dependent variables & Mean (SD) \\
\hline Antibiotic knowledge & $10.10(3.09)$ \\
\hline Antibiotic use (prescription) & $n(\%)$ \\
\hline Yes & $275(68.8)$ \\
\hline No & $125(31.3)$ \\
\hline
\end{tabular}

$\mathrm{SD}$ - standard deviation

\section{DISCUSSION}

This research is among the first to explore the different dimensions of antibiotic knowledge and their association with antibiotic use among various demographic groups in Ghana. Our study adds to evidence base by identifying important predictors of antibiotic knowledge to inform public health interventions aimed at promoting prudent use of antibiotics in communities.

The PCA results identified several gaps in knowledge across demographic groups. For example, the first principal component revealed that men and younger individuals aged 18-24 years were not well-informed about the treatment of common illnesses such as malaria, headaches, and body aches. Malaria, for instance, is endemic to Ghana and ranks among the top ten causes of disability-adjusted life years. ${ }^{18}$ A further analysis by age and gender revealed that $13.8 \%$ and $9.3 \%$ of total deaths among males and females aged 15-49 years, respectively, were attributed to malaria. ${ }^{18}$ Moreover, it is worth noting that while the annual percentage change was negative for females $(-0.5 \%)$, males reported a positive change $(1.0 \%)$, indicating a rise in mortality in the latter group. ${ }^{18}$ Antibiotics and antimalarials are the most frequently used in self-medication in resource-low settings. ${ }^{17}$ It is not evident whether the problem of mul- tidrug-resistant malaria ${ }^{33-37}$ may be driving individuals to resort to antibiotics to treat malaria. Nonetheless, more men than women in our study assumed antibiotics were effective against malaria. More studies are therefore needed to shed light on reasons behind self-medication decisions. There may also be several other factors driving gender differences in these population groups; hence future studies should consider exploring other possible demographic and socioeconomic factors to better inform public health interventions.

Regarding the second principal component, we observed significant differences in all but one covariate. Region, age, and education were found to predict knowledge about prudent use of antibiotics. This component suggests that individuals with higher knowledge about the effectiveness of antibiotics for treating bacterial infections (gonorrhea, bladder or urinary tract infections) also tended to be more knowledgeable about the inappropriateness of sharing antibiotics with friends and family or purchasing antibiotics without a medical prescription. Furthermore, knowledge about prudent use of antibiotics increased with age and educational attainment. On the other hand, a negative association was observed for region; residents of the Upper West region had lower knowledge compared to Greater Accra residents. These findings are consistent with previous 
Table 2. Knowledge frequency within region $(n=400)$

\begin{tabular}{|c|c|c|c|c|}
\hline \multirow[t]{3}{*}{ Questions } & \multicolumn{4}{|c|}{ Correct responses } \\
\hline & \multirow{2}{*}{$\begin{array}{l}\text { GAR } \\
(n=200) \\
n(\%)\end{array}$} & \multirow{2}{*}{$\begin{array}{l}\text { UWR } \\
(n= \\
200) \\
n(\%)\end{array}$} & \multirow{2}{*}{$\begin{array}{l}\begin{array}{l}\text { Total } \\
(\mathrm{n}=400)\end{array} \\
\mathrm{n}(\%)\end{array}$} & \multirow[t]{2}{*}{$\begin{array}{l}\mathrm{P}- \\
\text { value }\end{array}$} \\
\hline & & & & \\
\hline \multicolumn{5}{|l|}{-Do you think these conditions can be treated with antibiotics? } \\
\hline HIV/AIDS & $\begin{array}{l}129 \\
(64.5)\end{array}$ & $\begin{array}{l}167 \\
(83.5)\end{array}$ & $\begin{array}{l}296 \\
(74.0)\end{array}$ & $<0.001$ \\
\hline Gonorrhea & $\begin{array}{l}94 \\
(47.0)\end{array}$ & $\begin{array}{l}73 \\
(36.5)\end{array}$ & $\begin{array}{l}167 \\
(41.8)\end{array}$ & 0.03 \\
\hline Bladder infection or urinary tract infection & $\begin{array}{l}114 \\
(57.0)\end{array}$ & $\begin{array}{l}91 \\
(45.5)\end{array}$ & $\begin{array}{l}205 \\
(51.3)\end{array}$ & 0.02 \\
\hline Cold and flu & $\begin{array}{l}44 \\
(22.0)\end{array}$ & $\begin{array}{l}90 \\
(45.0)\end{array}$ & $\begin{array}{l}134 \\
(33.5)\end{array}$ & $<0.001$ \\
\hline Malaria & $\begin{array}{l}100 \\
(50.0)\end{array}$ & $\begin{array}{l}117 \\
(58.5)\end{array}$ & $\begin{array}{l}217 \\
(54.3)\end{array}$ & 0.09 \\
\hline Skin or wound infection & $\begin{array}{l}138 \\
(69.0)\end{array}$ & $\begin{array}{l}140 \\
(70.0)\end{array}$ & $\begin{array}{l}278 \\
(69.5)\end{array}$ & 0.83 \\
\hline Body aches & $\begin{array}{l}103 \\
(51.5)\end{array}$ & $\begin{array}{l}108 \\
(54.0)\end{array}$ & $\begin{array}{l}211 \\
(52.8)\end{array}$ & 0.62 \\
\hline Headaches & $\begin{array}{l}123 \\
(61.5)\end{array}$ & $\begin{array}{l}122 \\
(61.0)\end{array}$ & $\begin{array}{l}245 \\
(61.3)\end{array}$ & 0.92 \\
\hline $\begin{array}{l}\text { - Many infections are becoming increasingly resistant to treatment to } \\
\text { antibiotics }\end{array}$ & $\begin{array}{l}123 \\
(61.5)\end{array}$ & $\begin{array}{l}152 \\
(76.0)\end{array}$ & $\begin{array}{l}275 \\
(68.8)\end{array}$ & 0.002 \\
\hline $\begin{array}{l}\text { - If bacteria are resistant to antibiotics, it can be very difficult or impossible to } \\
\text { treat the infections they cause }\end{array}$ & $\begin{array}{l}136 \\
(68.0)\end{array}$ & $\begin{array}{l}155 \\
(77.5)\end{array}$ & $\begin{array}{l}291 \\
(72.8)\end{array}$ & 0.03 \\
\hline - Antibiotic resistance is an issue that could affect me or my family & $\begin{array}{l}126 \\
(63.0)\end{array}$ & $\begin{array}{l}149 \\
(74.5)\end{array}$ & $\begin{array}{l}275 \\
(68.8)\end{array}$ & 0.01 \\
\hline - Antibiotic resistance is an issue in other countries but not in Ghana & $\begin{array}{l}140 \\
(70.0)\end{array}$ & $\begin{array}{l}145 \\
(72.5)\end{array}$ & $\begin{array}{l}285 \\
(71.3)\end{array}$ & 0.58 \\
\hline $\begin{array}{l}\text { - Antibiotic resistance is only a problem for people who take antibiotics } \\
\text { regularly }\end{array}$ & $\begin{array}{l}95 \\
(47.5)\end{array}$ & $\begin{array}{l}63 \\
(31.5)\end{array}$ & $\begin{array}{l}158 \\
(39.5)\end{array}$ & 0.001 \\
\hline $\begin{array}{l}\text { - Antibiotic-resistant infections could make medical procedures like surgery, } \\
\text { organ transplants and other cancer treatment much more dangerous }\end{array}$ & $\begin{array}{l}96 \\
(48.0)\end{array}$ & $\begin{array}{l}122 \\
(61.0)\end{array}$ & $\begin{array}{l}218 \\
(54.5)\end{array}$ & 0.009 \\
\hline $\begin{array}{l}\text { - When do you think you should stop taking antibiotics once you have begun } \\
\text { treatment? }\end{array}$ & $\begin{array}{l}131 \\
(65.5)\end{array}$ & $\begin{array}{l}92 \\
(46.0)\end{array}$ & $\begin{array}{l}223 \\
(55.0)\end{array}$ & $<0.001$ \\
\hline $\begin{array}{l}\text { - It's ok to use antibiotics that were given to a friend or family member as long } \\
\text { as they were used to treat the same illness }\end{array}$ & $\begin{array}{l}166 \\
(83.0)\end{array}$ & $\begin{array}{l}138 \\
(69.0)\end{array}$ & $\begin{array}{l}304 \\
(76.0)\end{array}$ & 0.001 \\
\hline $\begin{array}{l}\text { - It's ok to buy the same antibiotics, or request these from a doctor/nurse, if } \\
\text { you're sick and they helped you get better when you had the same symptoms } \\
\text { before }\end{array}$ & $\begin{array}{l}141 \\
(70.5)\end{array}$ & $\begin{array}{l}115 \\
(57.5)\end{array}$ & $\begin{array}{l}256 \\
(64.0)\end{array}$ & 0.007 \\
\hline
\end{tabular}

GAR - Greater Accra Region, UWR - Upper West Region

studies that found low knowledge among rural residents, the younger-aged, and persons with low educational attainment. ${ }^{22,26,38}$ However, a few studies have found contrasting results with higher knowledge observed in younger individuals $;^{27,39}$ thus, indicating the uniqueness of populations and need for tailored solutions.

In contrast to observations for the first principal component, knowledge did not differ by gender for the second principal component. Both men and women would therefore benefit from educational interventions about prudent antibiotic use with particular attention on the risks of buying and sharing of antibiotics without initial medical attention. It is also worth noting that higher knowledge does not necessarily equate to prudent use. ${ }^{25}$ Various research studies vary in their definitions of knowledge and prudent use of antibiotics. Recognizing this distinction underscores 
Table 3. Principal component analysis results for components 1 and 2

\begin{tabular}{|c|c|c|}
\hline & Component 1 & Component 2 \\
\hline & $\begin{array}{l}\text { Knowledge about } \\
\text { treatment of } \\
\text { commonillnesses }\end{array}$ & Knowledge about prudent use of antibiotics \\
\hline & Variable (eigenvector) & Variable (eigenvector) \\
\hline & $\begin{array}{l}\text { Do you think these } \\
\text { conditions can be treated } \\
\text { with antibiotics? }\end{array}$ & Do you think these conditions can be treated with antibiotics? \\
\hline & - Malaria (0.40) & - Gonorrhea (0.36) \\
\hline & - Body aches (0.35) & - Bladder infection or urinary tract infection (0.45) \\
\hline & - Headaches (0.38) & \\
\hline & & Do you think these statements are 'True' or 'False'? \\
\hline & & $\begin{array}{l}\text { - It's ok to use antibiotics that were given to a friend or family member as long as } \\
\text { they were used to treat the same illness }(0.43)\end{array}$ \\
\hline & & $\begin{array}{l}\text {-It's ok to buy the same antibiotics, or request these from a doctor/nurse, if } \\
\text { you're sick and they helped you get better when you had the same symptoms } \\
\text { before }(0.36)\end{array}$ \\
\hline $\begin{array}{l}\text { Cronbach } \\
\text { alpha }\end{array}$ & 0.72 & 0.51 \\
\hline$\%$ Variance & 16.3 & 10.9 \\
\hline $\begin{array}{l}\% \\
\text { Cumulative } \\
\text { variance }\end{array}$ & 16.3 & 27.2 \\
\hline
\end{tabular}

Table 4. Multivariate analyses results for principal components 1 and $2(n=400)$

\begin{tabular}{|c|c|c|c|c|c|c|}
\hline \multirow[b]{2}{*}{ Covariate } & \multicolumn{3}{|c|}{ Principal component 1} & \multicolumn{3}{|c|}{ Principal component 2} \\
\hline & beta, $b$ & $95 \% \mathrm{Cl}$ & P-value & beta, $b$ & $95 \% \mathrm{Cl}$ & P-value \\
\hline \multicolumn{7}{|l|}{ Region } \\
\hline \multicolumn{7}{|l|}{ Greater Accra (ref. group) } \\
\hline Upper West & 0.08 & $(-0.17,0.34)$ & 0.52 & -0.3 & $(-0.54,-0.04)$ & 0.02 \\
\hline \multicolumn{7}{|l|}{ Gender } \\
\hline \multicolumn{7}{|l|}{ Male (ref. group) } \\
\hline Female & 0.25 & $(0.01,0.48)$ & 0.04 & 0.12 & $(-0.12,0.36)$ & 0.32 \\
\hline \multicolumn{7}{|l|}{ Age } \\
\hline \multicolumn{7}{|l|}{ 18-24 (ref. group) } \\
\hline $25-34$ & 0.38 & $(0.09,0.67)$ & 0.01 & 0.22 & $(-0.07,0.51)$ & 0.14 \\
\hline $35-44$ & 0.49 & $(0.12,0.86)$ & 0.01 & 0.52 & $(0.16,0.89)$ & 0.01 \\
\hline $45-54$ & 0.48 & $(0.02,0.94)$ & 0.04 & 0.59 & $(0.13,1.05)$ & 0.01 \\
\hline $55-64$ & 0.45 & $(-0.07,0.98)$ & 0.09 & 0.78 & $(0.25,1.30)$ & 0.004 \\
\hline $65+$ & 0.77 & $(-0.16,1.70)$ & 0.11 & 0.02 & $(-0.91,0.94)$ & 0.97 \\
\hline \multicolumn{7}{|l|}{ Education } \\
\hline \multicolumn{7}{|l|}{ Primary/lower (ref. group) } \\
\hline Junior high school & 0.34 & $(-0.26,0.94)$ & 0.27 & 0.4 & $(-0.20,0.99)$ & 0.19 \\
\hline Senior high/vocational & 0.08 & $(-0.36,0.51)$ & 0.73 & 0.7 & $(0.36,1.21)$ & $<0.001$ \\
\hline Tertiary/currentaassddsly enrolled & 0.004 & $(-0.43,0.44)$ & 0.98 & 0.81 & $(0.38,1.24)$ & $<0.001$ \\
\hline
\end{tabular}

the need to adopt statistical techniques such as the PCA to disintegrate large data sets into specific components that identify current gaps in knowledge to guide the design and implementation of health education interventions. In addi- tion, public education about the different classifications of infections is necessary to inform individuals about the need for a medical diagnosis to advise appropriate treatment. Likewise, given the high number of incorrect responses re- 
Table 5. Multiple logistic regression results for the association between principal components and antibiotic use $(n=400)$

\begin{tabular}{|c|c|c|c|}
\hline \multirow[t]{2}{*}{ Covariate } & \multicolumn{3}{|c|}{ Adjusted } \\
\hline & OR & $95 \% \mathrm{Cl}$ & P-value \\
\hline \multicolumn{4}{|l|}{ Principal Components } \\
\hline Component 1 & 1.16 & $(0.96,1.40)$ & 0.13 \\
\hline Component 2 & 1.4 & $(1.15,1.69)$ & 0.001 \\
\hline \multicolumn{4}{|l|}{ Region } \\
\hline \multicolumn{4}{|l|}{ Greater Accra (ref. group) } \\
\hline Upper West & 0.96 & $(0.59,1.56)$ & 0.88 \\
\hline \multicolumn{4}{|l|}{ Gender } \\
\hline Male (ref. group) & & & 0.1 \\
\hline Female & 1.47 & $(0.93,2.33)$ & \\
\hline \multicolumn{4}{|l|}{ Age } \\
\hline \multicolumn{4}{|l|}{ 18-24 (ref. group) } \\
\hline $25-34$ & 1.55 & $(0.90,2.67)$ & 0.12 \\
\hline $35-44$ & 2.02 & $(0.96,4.25)$ & 0.06 \\
\hline $45-54$ & 1.75 & $(0.70,4.37)$ & 0.23 \\
\hline $55-64$ & 1.1 & $(0.41,2.96)$ & 0.84 \\
\hline $65+$ & 0.76 & $(0.14,4.08)$ & 0.75 \\
\hline \multicolumn{4}{|l|}{ Education } \\
\hline \multicolumn{4}{|l|}{ Primary/lower (ref. group) } \\
\hline Junior high school & 0.38 & $(0.12,1.16)$ & 0.09 \\
\hline Senior high/vocational school & 0.74 & $(0.31,1.74)$ & 0.49 \\
\hline Tertiary/currently enrolled & 0.72 & $(0.30,1.71)$ & 0.46 \\
\hline
\end{tabular}

ported (Table 2), emphasis should be placed on bladder/urinary tract infections and sexually transmitted infections as gonorrhea.

An examination of the association between knowledge and use of antibiotics showed a strong significance for the second principal component. Our results revealed that individuals who had received a medical prescription during the last occurrence of illness had higher knowledge about the treatment of gonorrhea and bladder/urinary tract infections and were also knowledgeable about the risks of sharing and buying antibiotics. This indicates that higher knowledge may translate to better use. Hence, one way to reduce the misuse of antibiotics in communities is by focusing health messages towards individuals who are more likely to buy and share antibiotics. For this study, prudent use was defined as whether an individual received a prescription during the last time of infection. It is probable that individuals may not seek medical attention for common illnesses as headaches, body aches, and malaria, which may have explained the absence of a significant difference between the first component and antibiotic use. However, as discussed above, we found differences in knowledge about the treatment of common illnesses within demographic groups, particularly among men and the younger-aged. Lack of knowledge about the risks associated with inappropriate use of antibiotics could lead to their misuse for non-bacterial infections, consequently diminishing their effectiveness in times when they are most crucial. Thus, future public health campaigns will benefit from taking a more comprehensive approach when developing health messages to reach diverse populations.

\section{STRENGTHS AND LIMITATIONS OF THE STUDY}

A major strength of our study is its application of a principal component analysis technique to identify predictors of knowledge in relation to antibiotic use. Future research surveys will benefit from including a wider range of infections most prevalent in Ghana, specifically those that largely contribute to the country's disability-adjusted life years. ${ }^{18} \mathrm{Hav}$ ing a more comprehensive list will provide a clearer depiction of the extent of the public health problem and identify the various types of infections being treated inappropriately with antibiotics, as well as identify populations at most risk. In addition, our study included an even distribution of rural and urban residents, a comparable representation of men and women, and a range of age groups and educational levels. A limitation of the study is its cross-sectional design which does not provide a reflection of changes in participants' knowledge and use of antibiotics over time. Also, findings may not be representative of the entire country given that two regions were sampled. Finally, PCA treats components as observed, thereby increasing the likelihood of underestimated variances. The level of one's knowledge is driven by many factors including some that are not readily assessed via questionnaire. This may have resulted in the 
relatively small variation explained by the components and suggests improvement of future knowledge measurements.

\section{CONCLUSIONS}

This research provides useful information on the current knowledge about antibiotics in relation to antibiotic use in Ghanaian communities. Increased knowledge about antibiotics and prior experience with antibiotic therapy were identified as determinants associated with antibiotic use. Results also showed that men and the younger-aged were not well-informed about the treatment of common illnesses such as malaria, headaches, and body aches. Also, knowledge about prudent use of antibiotics increased with age and educational attainment. Further, results revealed that individuals who had received a medical prescription during the last occurrence of illness had better knowledge about the treatment of gonorrhea and bladder/urinary tract infections and were aware about the risks of sharing and buying antibiotics without a medical prescription. Our study identified several factors of inappropriate antibiotic use and provide important information about specific knowledge and behaviors to target during the development and implementation of public health interventions to promote prudent use of antibiotics in communities. We anticipate that these preliminary findings will form the basis for future research studies.

Acknowledgements: We are grateful to the Department of Population Health \& Disease Prevention at the University of California, Irvine for providing funding for the research study. We thank Dr. Annie Ro for helpful comments on the manuscript; and Dr. Anton Palma and Dr. Joni Ricks-Oddie for review of statistical methods. We also express appreciation to the WHO for granting permission to adapt the original survey. Our utmost gratitude goes to Dr. Ama Pokuaa Fenny for her invaluable insights, all study participants and research assistants (Justin Bamora, Sabina Bapono, Mohammed Ibrahim, Priscilla Manu Larbi, William Ofosu, Augustina Vi-ire, Ebo Abbiw-Williams, Monica Yere) for their dedicated contributions.

Funding: Department of Population Health \& Disease Prevention, University of California, Irvine.

Authorship contributions: The authors had full access to the data and contributed to the conceptualization, design, analysis, and writing of the final manuscript.

Competing interests: The authors completed the Unified Competing Interest form at www.icmje.org/coi_disclosure.pdf (available upon request from the corresponding author), and declare no conflicts of interest.

\section{Correspondence to:}

Oladele A. Ogunseitan, $\mathrm{PhD}$

University of California

Anteater Instruction and Research Building

653 E Peltason Drive

Irvine, CA 92697, USA

Oladele.ogunseitan@uci.edu

This is an open-access article distributed under the terms of the Creative Commons Attribution 4.0 International License (CCBY-4.0). View this license's legal deed at http://creativecommons.org/licenses/by/4.0 and legal code at http://creativecommons.org/licenses/by/4.0/legalcode for more information. 


\section{REFERENCES}

1. Laxminarayan R, Matsoso P, Pant S, Brower C, Røttingen J-A, Klugman K, et al. Access to effective antimicrobials: A worldwide challenge. Lancet (London, England). 2016;387:168-175. doi:10.1016/S0 140-6736(15)00474-2

2. Laxminarayan R, Duse A, Wattal C, Zaidi AKM, Wertheim HFL, Sumpradit N, et al. Antibiotic resistance-the need for global solutions. The Lancet Infectious diseases. 2013;13:1057-1098. doi:10.1016/ S1473-3099(13)70318-9

3. Melander RJ, Melander C. The Challenge of Overcoming Antibiotic Resistance: An Adjuvant Approach? ACS Infect Dis. 2017;3:559-563. doi:10.10 21/acsinfecdis.7b00071

4. Morehead MS, Scarbrough C. Emergence of Global Antibiotic Resistance. Prim Care. 2018;45:467-484. do i:10.1016/i.pop.2018.05.006

5. Wellington EMH, Boxall AB, Cross P, Feil EJ, Gaze $\mathrm{WH}$, Hawkey PM, et al. The role of the natural environment in the emergence of antibiotic resistance in gram-negative bacteria. The Lancet Infectious diseases. 2013;13:155-165. doi:10.1016/S1 473-3099(12)70317-1

6. Ventola CL. The antibiotic resistance crisis: Part 1: causes and threats. $P$ T. 2015;40:277-283.

7. Chellat MF, Raguz L, Riedl R. Targeting Antibiotic Resistance. Angew Chem Int Ed Engl. 2016;55:6600-6626. doi:10.1002/anie.201506818

8. Fernández J, Bert F, Nicolas-Chanoine M-H. The challenges of multi-drug-resistance in hepatology. $J$ Hepatol. 2016;65:1043-1054. doi:10.1016/j.jhep.201 6.08 .006

9. Mazzariol A, Bazaj A, Cornaglia G. Multi-drugresistant Gram-negative bacteria causing urinary tract infections: A review. J Chemother. 2017;29:2-9. doi:10.1080/1120009X.2017.1380395

10. Friedman ND, Temkin E, Carmeli Y. The negative impact of antibiotic resistance. Clinical microbiology and infection: the official publication of the European Society of Clinical Microbiology and Infectious Diseases. 2016;22:416-422. doi:10.1016/i.c $\underline{\text { mi.2015.12.002 }}$

11. O'Neill J. Tackling a crisis for the health and wealth of nations. Antimicrobial Resistance. 2014.
12. Munita JM, Arias CA. Mechanisms of Antibiotic Resistance. Microbiology Spectrum. 2016;4(2). doi:1 $\underline{0.1128 / \text { microbiolspec.vmbf-0016-2015 }}$

13. Versporten A, Zarb P, Caniaux I, Gros M-F, Drapier $\mathrm{N}$, Miller M, et al. Antimicrobial consumption and resistance in adult hospital inpatients in 53 countries: Results of an internet-based global point prevalence survey. The Lancet Global Health. 2018;6:e619-e629.

14. Holmes AH, Moore LSP, Sundsfjord A, Steinbakk M, Regmi S, Karkey A, et al. Understanding the mechanisms and drivers of antimicrobial resistance. Lancet (London, England). 2016;387:176-187. doi:1 $\underline{0.1016 / S 0140-6736(15) 00473-0}$

15. McEwen SA, Collignon PJ. Antimicrobial Resistance: A One Health Perspective. Microbiology Spectrum. 2018;6(2). doi:10.1128/microbiolspec.arb a-0009-2017

16. Adongo PB, Tabong PT-N, Asampong E, Ansong J, Robalo M, Adanu RM. Beyond knowledge and awareness: Addressing misconceptions in Ghana's preparation towards an outbreak of Ebola virus disease. PLoS One. 2016;11. doi:10.1371/journal.pon e.0149627

17. Ocan M, Obuku EA, Bwanga F, Akena D, Richard S, Ogwal-Okeng J, et al. Household antimicrobial selfmedication: A systematic review and meta-analysis of the burden, risk factors and outcomes in developing countries. BMC public health. 2015;15:742-. doi:10.11 86/s12889-015-2109-3

18. Institute for Health Metrics and Evaluation. Ghana | Institute for Health Metrics and Evaluation. 2017. http://www.healthdata.org/ghana.

19. Fair RJ, Tor Y. Antibiotics and bacterial resistance in the 21st century. Perspect Medicin Chem. 2014;6:25-64. doi:10.4137/PMC.S14459

20. Gualano MR, Gili R, Scaioli G, Bert F, Siliquini R. General population's knowledge and attitudes about antibiotics: A systematic review and meta-analysis. Pharmacoepidemiol Drug Saf. 2015;24:2-10. doi:10.1 $\underline{002 / p d s .3716}$

21. Robert A, Nguyen Y, Bajolet O, Vuillemin B, Defoin B, Vernet-Garnier V, et al. Knowledge of antibiotics and antibiotic resistance in patients followed by family physicians. Med Mal Infect. 2017;47:142-151. doi:10.1016/i.medmal.2016.10.003 
22. Demoré B, Mangin L, Tebano G, Pulcini C, Thilly N. Public knowledge and behaviours concerning antibiotic use and resistance in France: A crosssectional survey. Infection. 2017;45:513-520. doi:10.1 $\underline{007 / s 15010-017-1015-2}$

23. Erku DA, Mekuria AB, Belachew SA. Inappropriate use of antibiotics among communities of Gondar town, Ethiopia: A threat to the development of antimicrobial resistance. Antimicrobial resistance and infection control. 2017;6:112-. doi:10.1186/s1375 $\underline{\text { 6-017-0272-2 }}$

24. Lv B, Zhou Z, Xu G, Yang D, Wu L, Shen Q, et al. Knowledge, attitudes and practices concerning selfmedication with antibiotics among university students in western China. Trop Med Int Health. 2014;19:769-779. doi:10.1111/tmi.12322

25. McNulty CA, Boyle P, Nichols T, Clappison P, Davey P. Don't wear me out--the public's knowledge of and attitudes to antibiotic use. J Antimicrob Chemother. 2007;59:727-738. doi:10.1093/jac/dkl558

26. Pavydè E, Veikutis V, Mačiulienė A, Mačiulis V, Petrikonis K, Stankevičius E. Public Knowledge, Beliefs and Behavior on Antibiotic Use and SelfMedication in Lithuania. International journal of environmental research and public health. 2015;12:7002-7016. doi:10.3390/ijerph120607002

27. Cheng J, Coope C, Chai J, Oliver I, Kessel A, Wang $\mathrm{D}$, et al. Knowledge and behaviors in relation to antibiotic use among rural residents in Anhui, China. Pharmacoepidemiology and drug safety. 2018;27:652-659. doi:10.1002/pds.4429

28. Ministry of Health MoFaA, Ministry of Environment, Science, Technology and Innovation, Ministry of Fisheries and Aquaculture Development. Ghana National Action Plan on Antimicrobial Resistance. 2017.

29. Ministry of Health MoFaAMoE, Science, Technology and Innovation, Ministry of Fisheries and Aquaculture Development. Policy on Antimicrobial Use and Resistance. 2017.

30. Organisation WH. Global Action Plan on Antimicrobial Resistance. 2015.
31. Nations FaAOotU. Ghana pilots innovative tool to combat Antimicrobial Resistance 2019.

32. Jolliffe IT, Cadima J. Principal component analysis: A review and recent developments. Philos Trans A Math Phys Eng Sci. 2016;374:20150202-. do i:10.1098/rsta.2015.0202

33. Alam MT, de Souza DK, Vinayak S, Griffing SM, Poe AC, Duah NO, et al. Selective sweeps and genetic lineages of Plasmodium falciparum drug -resistant alleles in Ghana. J Infect Dis. 2011;203:220-227. doi:1 $\underline{0.1093 / \text { infdis/jiq038 }}$

34. Lynch C, Roper C. The transit phase of migration: Circulation of malaria and its multidrug-resistant forms in Africa. PLoS Med. 2011;8(5):e1001040. doi:1 0.1371/journal.pmed.1001040

35. Thu AM, Phyo AP, Landier J, Parker DM, Nosten FH. Combating multidrug-resistant Plasmodium falciparum malaria. FEBS J. 2017;284:2569-2578. do $\mathrm{i}: 10.1111 /$ febs. 14127

36. Hamilton WL, Amato R, van der Pluijm RW, Jacob CG, Quang HH, Thuy-Nhien NT, et al. Evolution and expansion of multidrug-resistant malaria in southeast Asia: A genomic epidemiology study. The Lancet Infectious diseases. 2019;19:943-951. doi:10.1 016/S1473-3099(19)30392-5

37. Ouji M, Augereau J-M, Paloque L, Benoit-Vical F. Plasmodium falciparum resistance to artemisininbased combination therapies: A sword of Damocles in the path toward malaria elimination. Parasite. 2018;25:24-. doi:10.1051/parasite/2018021

38. Yu M, Zhao G, Stålsby Lundborg C, Zhu Y, Zhao Q, $\mathrm{Xu} \mathrm{B}$. Knowledge, attitudes, and practices of parents in rural China on the use of antibiotics in children: A cross-sectional study. BMC infectious diseases. 2014;14:112-. doi:10.1186/1471-2334-14-112

39. Vallin M, Polyzoi M, Marrone G, Rosales-Klintz S, Tegmark Wisell K, Stålsby Lundborg C. Knowledge and Attitudes towards Antibiotic Use and Resistance A Latent Class Analysis of a Swedish PopulationBased Sample. Butaye P, ed. PLoS ONE. 2016;11(4):e0152160. doi:10.1371/journal.pone.0152 160 